Research, part of a Special Feature on Traditional Ecological Knowledge and Global Environmental Change: North and South Perspectives

\title{
Indigenous Past Climate Knowledge as Cultural Built-in Object and Its Accuracy
}

\author{
$\underline{\text { Christian Leclerc }}^{1}$, Caroline Mwongera $^{2}$, Pierre Camberlin $^{3}$ and $\underline{\text { Joseph Boyard-Micheau }}^{3}$
}

\begin{abstract}
In studying indigenous climate knowledge, two approaches can be envisioned. In the first, traditional knowledge is a cultural built-in object; conceived as a whole, its relevance can be assessed by referring to other cultural, economic, or technical components at work within an indigenous society. In the second, the accuracy of indigenous climate knowledge is assessed with western science knowledge used as an external reference. However, assessing the accuracy of indigenous climate knowledge remains a largely untapped area. We aim to show how accurate the culturally built indigenous climate knowledge of extreme climatic events is, and how amenable it is to fuzzy logic. A retrospective survey was carried out individually and randomly among 195 Eastern African farmers on climatic reasons for loss of on-farm crop diversity from 1961 to 2006. More than 3000 crop loss events were recorded, and reasons given by farmers were mainly related to droughts or heavy rainfall. Chisquare statistics computed by Monte Carlo simulations based on 999 replicates clearly rejected independence between indigenous knowledge of drought and heavy rainfall that occurred in the past and rainfall records. The fuzzy logic nature of indigenous climatic knowledge appears in the clear association of drought or heavy rainfall events, as perceived by farmers, with corresponding extreme rainfall values, contrasting with a fuzzy picture in the intermediate climatic situations. We discuss how the cultural built-in knowledge helps farmers in perceiving and remembering past climate variations, considering the specificity of the contexts where extreme climatic events were experienced. The integration of indigenous and scientific climate knowledge could allow development of drought monitoring that considers both climatic and contextual data.
\end{abstract}

Key Words: climate change; drought; ecological anthropology; fuzzy logic; Kenya; Meru; traditional ecological knowledge;

\section{INTRODUCTION}

Since the Fourth Assessment Report of the Intergovernmental Panel on Climate Change (Parry et al. 2007), comparisons of indigenous and western-scientific climate knowledge have been used as a means to favor their integration into a participatory research process (Ford and Furgal 2009, Salick and Ross 2009, Green and Raygorodetsky 2010). Quantitative data generated in a western scientific approach can complement indigenous qualitative data in a more powerful combined analysis (Berkes and Kislalioglu Berkes 2008).

Several features of indigenous climate knowledge are common to traditional environmental knowledge (TEK). Both tend to be holistic-integrative, site-specific, orally transmitted, functional, and dynamic, based on an intimate experience with the environment through extensive observations, which are directly, or indirectly, associated to climate change or climate variability (Ellen and Harris 2000, Huntington 2000, Huntington et al. 2004, Berkes and Kislalioglu Berkes 2008, Berkes 2009, Roncoli et al. 2009, Green and Raygorodetsky 2010). According to Berkes and Kislalioglu Berkes (2008), indigenous climate knowledge is consistent with fuzzy logic and pursues holism through the construction of collective mental models, combining a large number of variables qualitatively, as opposed to western science that focuses on a small number of quantitative variables. The highly social nature of indigenous climate knowledge allows for it to be considered as a culturally built-in object, in which different, social and climatic, components can be interrelated (Orlove et al. 2010). Although western science tends to emphasize compartmentalized knowledge that is often decontextualized (Barnhardt 2005), indigenous knowledge is acquired through direct experience, constituting an integral part of culture.

The interest in integrating indigenous and scientific climate knowledge was mainly recognized in studies focusing on climate change. In the Canadian Arctic (see Ford and Furgal 2009), or in Australia (Green et al. 2010), indigenous observations of seasonal change have the potential to fill gaps in climate data. The complementarities of the two kinds of knowledge were differently explored in studies concerned with climate variability. Indeed, indigenous knowledge on climate variability was valorized rather for its prospective value in seasonal rainfall forecasting (Orlove et al. 2000, 2004, 2010, Roncoli et al. 2002, Vogel and O'Brien 2003, Roncoli 2006) than for its accuracy in identifying past extreme climatic events as indigenous people experienced them. However, assessing the accuracy of the indigenous climate knowledge remains a largely untapped area (Huntington et al. 2004, Gearheard et al. 2010).

In this study we aim to show how accurate is the culturally built indigenous knowledge of past extreme climatic events

${ }^{1}$ CIRAD, UMR AGAP, Montpellier, France, ${ }^{2}$ Montpellier SupAgro, Montpellier, France, ${ }^{3}$ Centre de Recherches de Climatologie (CRC), Biogéosciences, Dijon, France 
is, and how amenable it is to fuzzy logic. Extreme climatic events, such as drought and heavy rainfall, were considered as indigenous cultural-holistic concepts, based on farmers' experiences and knowledge. Thus we closely refer to the definition of Berkes and Kislalioglu Berkes (2008) in considering that holism and fuzzy logic are key characteristics of indigenous climate knowledge, which is not individual but collective.

Lotfi A. Zadeh (1965) introduced the term "fuzzy logic" in his proposal of fuzzy set theory, which has been applied to many fields. Fuzzy set is a "class with a continuum of grades [or degree] of membership" (Zadeh 1965:339). Although the classical logic only permits propositions to be true or false, the fuzzy logic allows answer to be variable, for example when asking various people to identify color. A classical use of the fuzzy logic is to characterize subranges of a continuous variable, which is usually illustrated by the problem of setting the temperature in a conference room. People can unanimously agree that the conference room is too cold (or too hot) when the temperature is very low (or very high). Between the two extremes situations, however, the proportion of people who are feeling too cold should decrease as the temperature increases, and reverse for the proportion of people who are feeling too hot, considering that the temperature is differently experienced by individuals. The proposition "the conference room is too cold" may have a truth value that ranges in degree between 0 and 1 . Thus, fuzzy logic uses human experience and users' judgment in plausible reasoning, when the phenomenon that is characterized involves uncertainty, vagueness, impression, and subjectivity (Bojadziev and Bojadziev, 2007). It has also been used in ecology to develop models based on people's knowledge (Özesmi and Özesmi 2004).

Fuzzy logic can be applied to past indigenous climate knowledge, which also implies considering that people experienced it differently, and that the notion of "drought" can be variable. If indigenous climate knowledge is consistent with fuzzy logic, a higher level of consensus is expected for extreme climatic situations than for intermediate situations. Conversely, the transition between climatic events should be more gradual than abrupt in the indigenous climate knowledge systems (Berkes and Kislalioglu Berkes 2008).

\section{Context of the study site and specific question}

The cultural, economic, and climatic context of the eastern slope of Mount Kenya is particularly relevant for implementing such an approach. The agriculture of Meru communities established along the mountain slopes is mainly rain-fed. Rainfall is bimodal with a rainy season from March to May (hereafter, long rains) and another from October to December (short rains; Camberlin et al. 2009, 2012).

Eastern Kenya has a long history of climate stress events, and farmers remember periods of drought and famine. The great famine at the end of the 19th century, described in detail by Ambler (1988) using farmers' oral tradition, is a good illustration. More than 100 years later, the key challenge for farmers remains ensuring success of their rain-fed farming systems by preserving the diversity of their crop varieties, well adapted to their homeland. Remembering past extreme climatic events to mitigate negative effects of future drought is thus crucial for farmers.

Meru farmers have a drought nomenclature that can allow remembrance of past rainfall variations. Past climate knowledge is also embedded within their social organization. Indeed, in the Meru worldview, political authority is transmitted between generations according to regular rain and sun cycles, which, respectively, correspond to the return of drought or heavy rainfall (Peatrik 1999). Studying past climate knowledge as cultural built-in objet is thus relevant among Meru farmers, but a methodological difficulty exists. As stated by Diamond and Bishop (1999) concerning indigenous knowledge studies, there is an obvious risk in posing a leading question or one with a yes/no answer because it provides no internal check on the correctness of the answers. Studying farmers' perception of climate change in rural Sahel, Mertz et al. (2009) concluded that the farmers' communities have a high awareness of climate issues, but climatic narratives are likely to influence responses when questions mention climate. Thus, in the present study, Meru farmers' knowledge of past extreme climatic events were not studied directly, but indirectly through their memory and explanation of past crop variety losses.

A survey was implemented to inventory, in retrospect, farmers' past crop variety losses and to record their causes, as perceived by farmers. Climatic causes, such as drought and heavy rainfall, were predominantly mentioned by farmers to explain past varietal losses. Assuming that climatic causes mentioned by individual farmers are those at work in the farmers' collective mental model used to understand climate variability, we could compare the extreme climatic events, drought and heavy rainfall, as perceived by Meru farmers, with those obtained from meteorological measurements.

Crop life cycles can be short (October to February or March to June, which are initiated by the short rains and the long rains, respectively) or long (October to July, spanning both rain seasons). The assessment of farmer knowledge accuracy was limited to the long rains because both short and long cycle varieties are sown in October, at the beginning of the long rains. We thus paid particular attention to crop failures and climate variability during the seedling emergence phase.

Conceiving extreme climatic events as fuzzy sets widens the scope of applicability, notably in the field of drought classification and drought monitoring. The multifaceted nature of the farmer culturally built-in knowledge implies that it cannot be associated to a single scientific climatic variable. 
To capture all the relevant dimensions of the indigenous knowledge, social and agricultural contexts, as well as climatic data, have to be considered together for drought monitoring.

\section{MATERIALS AND METHODS}

\section{Rainfall data}

The Kenya Meteorological Department provided rainfall data from three stations in the neighborhood of surveyed farmers. The three stations, namely Ishiara (S 0.45, E 37.78, alt. 872 m), Mitunguu (S 0.10, E 37.78, alt. 1189 m), and Embu (S 0.50 , E 37.45, alt. $1433 \mathrm{~m}$ ), are located at three different altitudinal levels (hereafter, lower, mid, and higher levels, respectively). Farmers were randomly sampled along a similar three-level altitudinal gradient to ensure a high correlation between the altitudes of study sites and rainfall stations (Fig. $1)$.

Fig. 1. Study site, eastern slope of Mount Kenya. Farmers surveyed (solid circles) and rainfall stations (solid squares): 1. Ishiara (872 m); 2. Mitunguu (1189 m); 3. Embu (1433 $\mathrm{m})$.

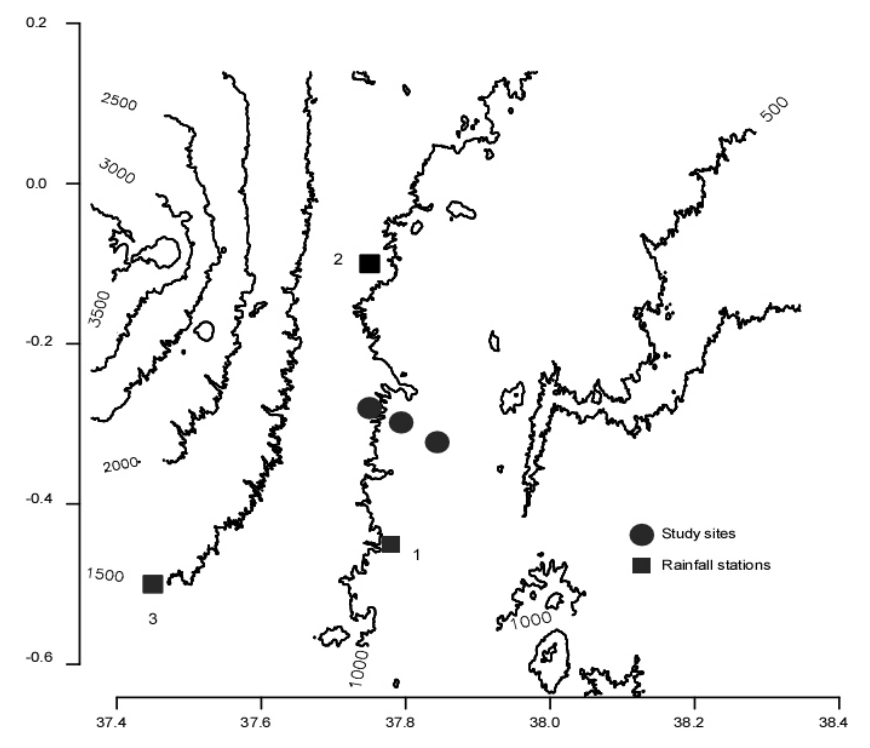

The stations' monthly and daily rainfall records encompassed the period 1961-2006. These quality-controlled records have been the object of a recent analysis by Camberlin et al (2012). A comparison with other stations located within the same altitudinal belts on the eastern slopes of Mount Kenya, but having shorter records, revealed strong correlations between the interannual rainfall variability at all these stations. This coherence makes us feel confident about the quality of the rainfall data. The high interstation correlations also enabled us to fill in missing values at Mitunguu and Ishiara through regression methods using nearby stations.
The onset and withdrawal of the long rains were determined for each year by considering the February-June subperiod. The seasonal precipitation amount (PTOT), the frequency of rainy days (FREQ), the rainfall intensity (INT), the seasonal duration (DUR), and the number of rainy days (NRD) were computed between the onset and the withdrawal dates. We analyzed these variables separately because we had no a priori knowledge of their particular association with crop variety losses.

\section{Climate knowledge surveys}

Two surveys were carried out following two different methods, indirect and direct, to assess Meru farmers' knowledge of past extreme climatic events. First, a retrospective survey was carried out in October 2009 to inventory crop varieties that had been lost over time, and the causes mentioned by farmers were recorded. Using the independent interview technique, each farmer was interviewed individually and not in a group setting, so the responses given by any individual farmer were not influenced by those given by others. A total of 195 farmers were surveyed at 3 altitudinal levels across 3 Meru communities: 45 at 700 $\mathrm{m}, 89$ at $950 \mathrm{~m}$, and 61 at $1100 \mathrm{~m}$. In retrospect, from 1961 to 2006, 8 main crops, namely beans (Phaseolus sp), cowpea (Vigna unguiculata (L.) Walp), finger millet (Eleusine coracana (L.) Gaertn), green gram (Vigna radiata (L.) R. Wilcz), maize (Zea mays L), pearl millet (Pennisetum glaucum (L.) R. Br), pigeon pea (Cajanus cajan, (L.) Millsp), and sorghum (Sorghum bicolor (L.) Moench), have been identified as components of the rain-fed farming systems. For each crop variety, the year of variety loss and its causes were recorded.

Second, a survey on farmers' drought nomenclature and history was carried out in September 2011. Interviews were conducted individually as well as in group settings. A total of 36 individual farmers (23 men and 13 women) were interviewed at the same 3 altitudinal levels. A second field visit was carried out to confirm the years that corresponded to drought nomenclature used by the Meru to remember past extreme climatic events. The second group of interviews involved 12 elderly farmers who were selected based on their knowledge of relations between past extreme climatic events, such as drought and heavy rainfall, and the Meru social and political organizations.

\section{Data analysis}

For all crop species, 3204 crop variety loss events were orally reported by farmers in retrospect from 1961 to 2006, and the causes for losses recorded yearly. The analysis was implemented in two steps: (1) assessing whether causes mentioned by farmers were independent from rainfall values recorded for the same years (chi-square test); (2) assessing the level of consensus among farmers in extreme and intermediate climatic situations (regression of Pearson's residuals against rain parameters) and testing whether their collective 
knowledge of past climatic events was consistent with fuzzy logic.

\section{Independence between causes mentioned by farmers and rainfall records}

We tabulated the causes assigned by the farmers against rainfall variables to assess their association. To control the increase of rainfall amounts with altitude (Camberlin et al. 2012), climatic variables were ranked into ordered categories of equal size, considering each altitudinal level separately. The resulting contingency tables displayed the counts of the farmers' declarations (e.g., drought or other events, as lines in the tables) as a function of the ordered rainfall categories (as columns in the tables). The match between the climatic causes given by farmers and rainfall categories was then assessed using the independence Chi-square test, following Agresti (2007). A Monte Carlo simulation computed with 999 replicates was used to confirm the Chi-square test by avoiding a potential bias due to a low expected frequency (less than five) in some cells. The procedure consists of the comparison of the observed data with random replicated samples generated in accordance with the hypothesis of independence between farmers' past climate knowledge and rainfall records. A Chisquare test was computed for each replicate. The outcome was the rank of the Chi-square test of the observed data relative to the random samples forming the reference set for the null hypothesis. The opposite nature of climatic causes mentioned by farmers (drought and heavy rainfall) allowed us to assess in two complementary ways the accuracy of farmers' climate knowledge and the fuzzy logic underlying this knowledge.

\section{Farmers' consensus for identifying past extreme climatic} events

We paid particular attention to the cell Pearson's residual, which measures the deviation of the observed frequency (proportion of farmers that have cited drought or heavy rainfall for each actual rainfall category) from the frequency that would be expected from random answers (guessing). For each row $i$ and each column $j$ of the contingency table, the Pearson's residual for a cell $\left(C_{i j}\right)$ is given as:

$$
C_{i j}=\frac{\text { observed }_{i j}-\text { expected }_{i j}}{\sqrt{\operatorname{expected}_{i j}}}
$$

Although the Chi-square test globally assesses whether farmers' declarations are independent from rainfall categories, the Pearson's residual allows identifying which cells individually contribute to reject the independence. For each cell, thus, the greater the difference between observed and expected frequencies, the lower the part of guessing.

Pearson's residual was positive, when farmers collectively agreed in associating extreme climatic events to a given rainfall category, or negative, when they collectively do not.
Thus, a greater residual in absolute value reflects a higher level of consensus among farmers. Their knowledge is significantly different from guessing $(\mathrm{p}<0.05)$ when the cell residual is higher than 2 in absolute value (Agresti 2007; see also Patefield 1981, Meyer et al. 2006).

The fuzzy logic nature of indigenous climatic knowledge should be reflected in a strong consensus among farmers for extreme events (droughts and heavy rainfall) vs. a weaker consensus for the intermediate climatic situations. In statistical terms, this should translate into higher absolute values of the Pearson's residual for severe droughts and heavy rainfall (strong deviation from random distribution of farmer's answers), and lower residual values for more favorable climatic situations (lower consensus among farmers, resulting in a higher dispersion of their answers).

If farmers' record of past climatic events is not independent from gauge records, drought-related losses should logically be positively associated to the low rainfall values, and negatively to the high rainfall values, and, conversely, heavy rainfall-related losses should be positively associated to the high rainfall values and negatively to the low rainfall values. For the intermediate climatic situations, drought and heavy rainfall should correspond to a fuzzy picture with a Pearson's residual close to 0 . Thus, a positive linear correlation between Pearson's residual and rainfall categories in ascending order should be observed, when farmers mentioned heavy rainfall, and a negative linear correlation, when they mentioned drought. This was tested for all the climatic variables, by plotting cell residuals against the ordered rainfall values to confirm that cell residuals increase as rainfall values increase for heavy rainfall, and decrease for drought.

Rainfall variables are continuous quantitative variables. To compute the cell Pearson residual, these variables had to be transformed into a qualitative ordered variable. However, the match between the climatic causes given by farmers and rainfall categories could depend on the number of rainfall categories used for this transformation. To control for this potential bias, contingency tables using different numbers of rainfall ordered categories (from 4 to 10 rainfall categories) were compared to confirm that the linear correlation coefficients (positive or negative for heavy rainfall and drought, respectively) did not depend on the number of rainfall categories considered in the analysis. It is only for commodity that the number of rainfall categories used in graphical displays was the one corresponding to the lowest residual mean square in the regression. The analysis was implemented with $\mathrm{R}(\mathrm{R}$ Development Core Team 2011).

\section{RESULTS}

\section{Reported causes of crop variety losses}

Figure 2 shows the years in which droughts were associated with crop diversity losses by farmers. Their distribution is far 
Table 1. Variety losses and causes reported by farmers, for the 1961-2006 period, and their distribution among six categories of increasing seasonal rainfall. A. Upper bounds of rainfall categories $(\mathrm{mm})$. B. Causes reported by farmers to explain variety losses.

\begin{tabular}{lcccccc}
\hline \hline & \multicolumn{7}{c}{ Rainfall categories } \\
\hline A. Upper bounds (mm) & 1 & 2 & 3 & 4 & 5 & 6 \\
& 202 & 261 & 321 & 410 & 479 & 614 \\
Low alt. (mm) & 373 & 461 & 529 & 670 & 851 & 1204 \\
Mid alt. (mm) & 451 & 530 & 590 & 688 & 817 & 1118
\end{tabular}

\section{B. Reported causes}

\begin{tabular}{|c|c|c|c|c|c|c|c|c|c|}
\hline & & 1 & 2 & 3 & 4 & 5 & 6 & Total & $\%$ \\
\hline Drought & & 1086 & 365 & 151 & 394 & 322 & 35 & 2353 & 73.49 \\
\hline Heavy rainfall & & 71 & 28 & 26 & 46 & 97 & 4 & 272 & 8.49 \\
\hline Consumed-sold & & 51 & 24 & 23 & 23 & 33 & 19 & 173 & 5.4 \\
\hline Pest-disease & & 51 & 37 & 22 & 21 & 22 & 17 & 170 & 5.31 \\
\hline Variety changed & & 43 & 19 & 13 & 30 & 23 & 7 & 135 & 4.22 \\
\hline \multirow[t]{3}{*}{ Others } & & 23 & 7 & 10 & 35 & 12 & 12 & 99 & 3.09 \\
\hline & Total & 1325 & 480 & 245 & 549 & 509 & 94 & 3202 & 100 \\
\hline & $\%$ & 41.38 & 14.99 & 7.65 & 17.15 & 15.9 & 2.94 & 100 & \\
\hline
\end{tabular}

Fig. 2. Frequency of drought reported by farmers (1961-2006). Names reported on the figure are those used in Meru drought nomenclature (see Table 3).

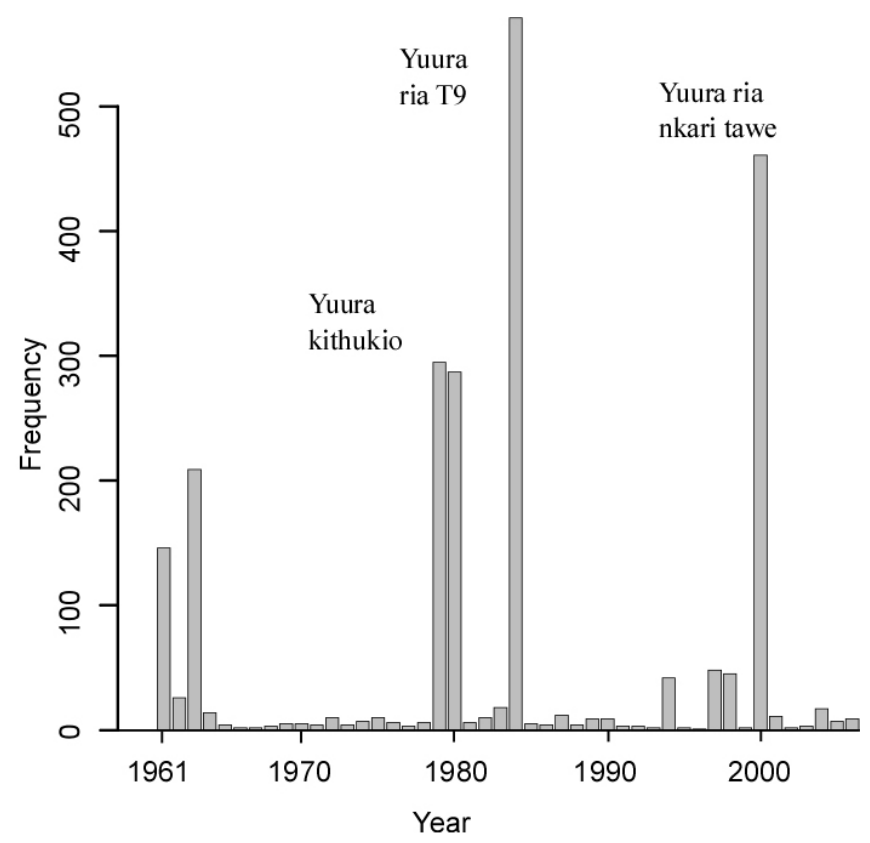

from random, consisting of six major drought years. Meru drought names were reported on this figure, which summarizes the combined perceptions of the past rainfall variations by all individual farmers. These years correspond to major droughts inventoried by several authors for Kenya (Mbithi and Wisner 1973, Newman 1975, Nyamwange 1995, Ogallo et al. 2005), the 1984 drought being considered as the worst in the last century.

The two-way contingency table (Table 1) cross-classifies the causes mentioned by farmers to explain variety losses in the past (rows) and the seasonal rainfall categories (from 1 to 6 in ascending order in columns). According to farmers, $82 \%$ of variety losses were due to rainfall anomalies, as compared to $5.4 \%$ and $5.3 \%$ due to grain consumption or diseases, respectively. Drought was mentioned $73.5 \%$ of the time whereas $8.5 \%$ of the losses were attributed to heavy rainfall. On the whole, although seasonal precipitation can be quantitatively different among the three altitudinal levels (Table 1A), variety losses reported by farmers mainly occurred during the years when low rainfall values were recorded (56.4\% for the first two rainfall categories).

\section{Farmers' climatic knowledge and seasonal rainfall}

To show how accurate the farmers' knowledge is of past extreme climatic events, and how amenable it is to fuzzy logic, we considered the association between climatic causes that were mentioned by farmers and the seasonal rainfall. Independence between all the reasons given by farmers and rainfall records was clearly rejected $($ Chi-square $=304.2, \mathrm{df}=$ 25 , p-value $<0.001)$. There was a strong consensus among farmers, associating droughts with the lowest rainfall values (1086 declarations out of $2353 ; 46 \%$ ), and rejecting the 
association of droughts with the highest rainfall values (35 declarations only; $1.5 \%$ ). Heavy rainfall was predominantly associated with the fifth rainfall category ( 97 declarations out of 272). Among the 1325 loss declarations that occurred during seasons with the lowest total precipitations (first rainfall category), only 71 correspond to heavy rainfall (5.3\%). We observed a weaker consensus for the intermediate climatic situations (categories 3 and 4) for drought and heavy rainfall.

\section{Box 1:}

There was a strong consensus among farmers for associating droughts, as they are perceived in Meru culture, with lower rainfall values, as recorded in meteorological stations.

According to the Pearson residuals, there was no significant relationship between climate variations and farmers' decisions of varietal substitution. Seed consumption and pests explained $10.7 \%$ of variety losses. Both appeared closely associated to greater rainfall values, Pearson's residual over 5 for the sixth rainfall category. However, there was a consensus among farmers for associating these causes also with intermediate climatic situations, Pearson's residual over 2 for the third rainfall category. Indeed, seed consumption and pests were not linearly related to the rainfall variations (not shown), whereas drought and heavy rainfall were linearly related to rainfall (Fig. 3).

Figure 3 shows how farmers' past climatic knowledge was consistent with rainfall variations. On the left panel, the proportion of farmers mentioning drought (expressed as the value of the Pearson's residual) increases sharply with severe drought conditions (represented by rainfall categories 1 and 2 , i.e., low seasonal rainfall totals). The residual was highly positive $(+3.6)$ for the lowest rainfall values and highly negative (-4.1) for the highest rainfall values.

The high positive residuals for lower rainfall categories imply that the number of farmers mentioning drought is very significantly higher than expected under the null hypothesis (guessing). Conversely, for the high rainfall categories, the number of farmers mentioning drought is significantly lower than expected, so Pearson's residuals take negative values. Thus, farmers not only agreed in associating droughts with the lower rainfall categories, but also never mistook flood-induced crop losses for drought-induced events.

The farmers' knowledge accuracy was similar when they mentioned heavy rainfall (Fig. 3, right panel). The proportion of farmers mentioning heavy rainfall increased steadily with the order of rainfall categories, the residual getting highly positive at high rainfall categories (residual at +5.3 for category 6 , with an exception for category 7 , however), and highly negative for the low rainfall category (residual at -3.9).
As for drought, farmers' declarations very significantly deviated from guessing, contrasting with a lower consensus among farmers in the intermediate climatic situations.

Box 2:

Meru farmers not only agreed in associating past droughts with the lower rainfall values, but also never mistook flood-induced crop losses for drought-induced events.

On the whole, conditional Chi-square tests based on Monte Carlo simulation clearly rejected independence $(p=0.001)$ between climatic reasons given by farmers and rain gauge recorded rainfall, for both droughts and heavy rainfall. A hypothesis to explain why the relationship was less linear for losses related to heavy rainfall than for losses related to drought could be that in a good years crop losses may only occur under specific conditions of intra-seasonal rainfall distribution. For instance, heavy rainfall may be related to

Fig. 3. Proportion of farmers relating varietal losses to past climatic accidents, as a function of observed rainfall. Pearson's residuals are presented as a function of rainfall categories in ascending order of total seasonal precipitation. Left panel: the residuals obtained for the frequency of farmers mentioning drought decrease as rainfall values increase. Right panel: residuals obtained for the frequency of farmers mentioning heavy rainfall increase as rainfall values increase.
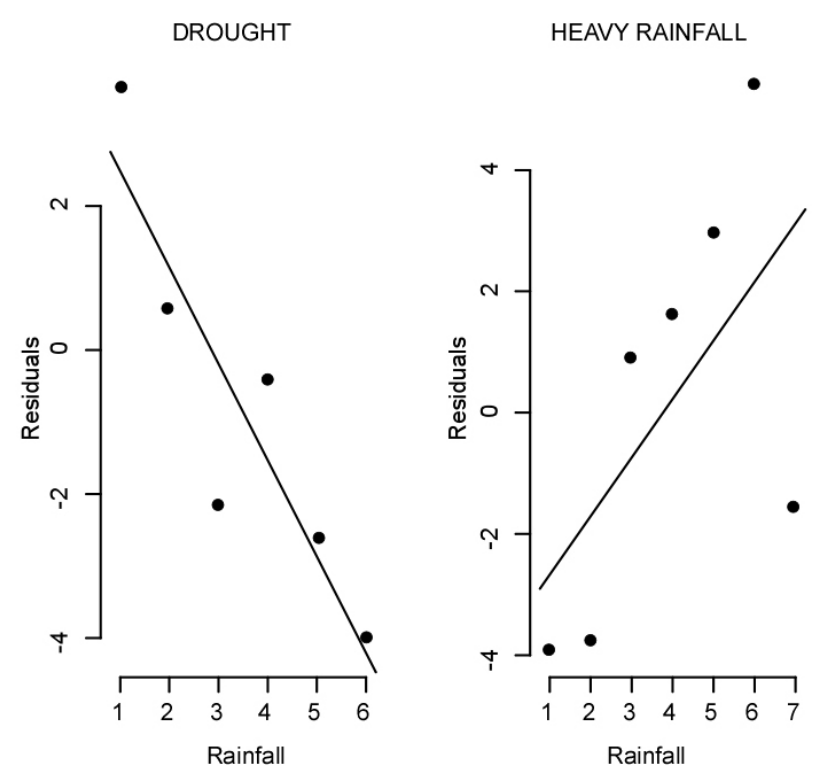
Fig. 4. Proportion of farmers relating varietal losses to past climatic accidents, as a function of rainfall categories. Pearson's residuals are presented as a function of rainfall categories in ascending order. A. Frequency of rainy days - FREQ; B. Rainfall intensity - INT; C. Seasonal duration - DUR; D. Number of rainy days - NRD.
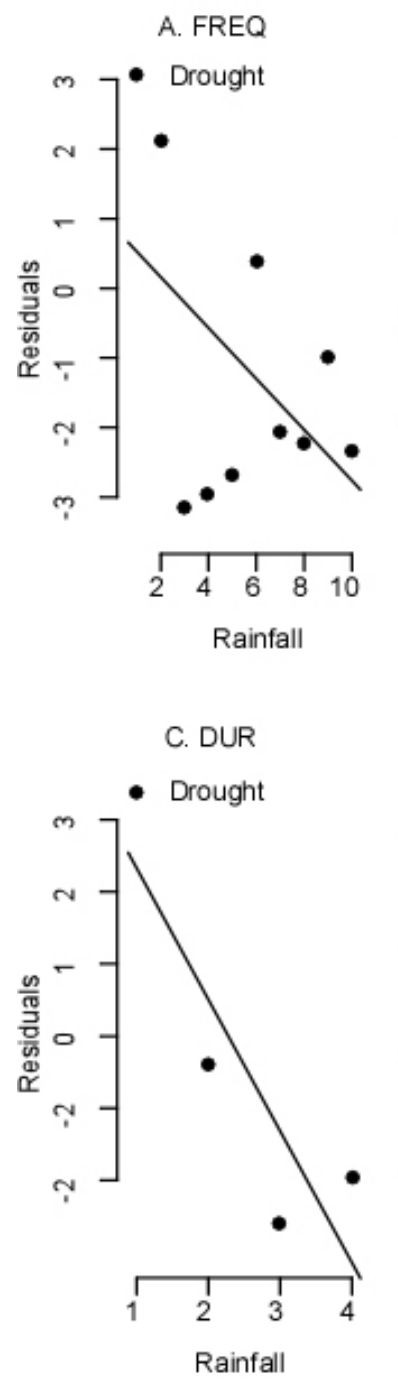
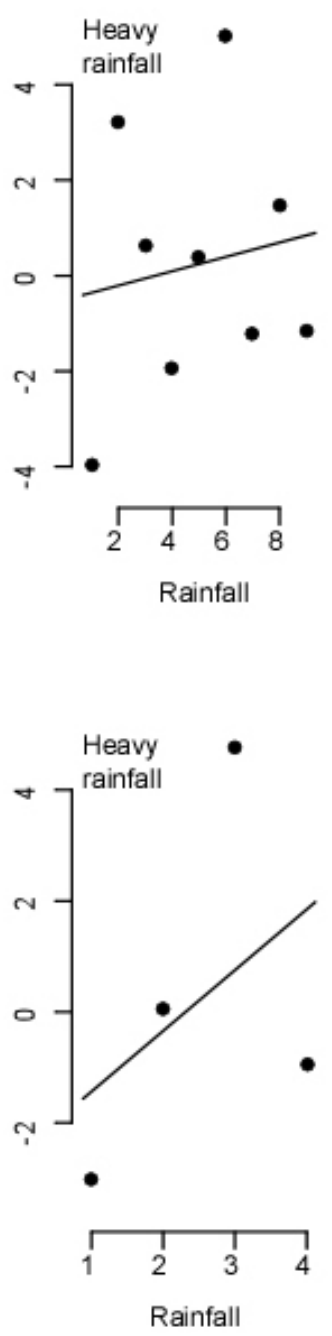
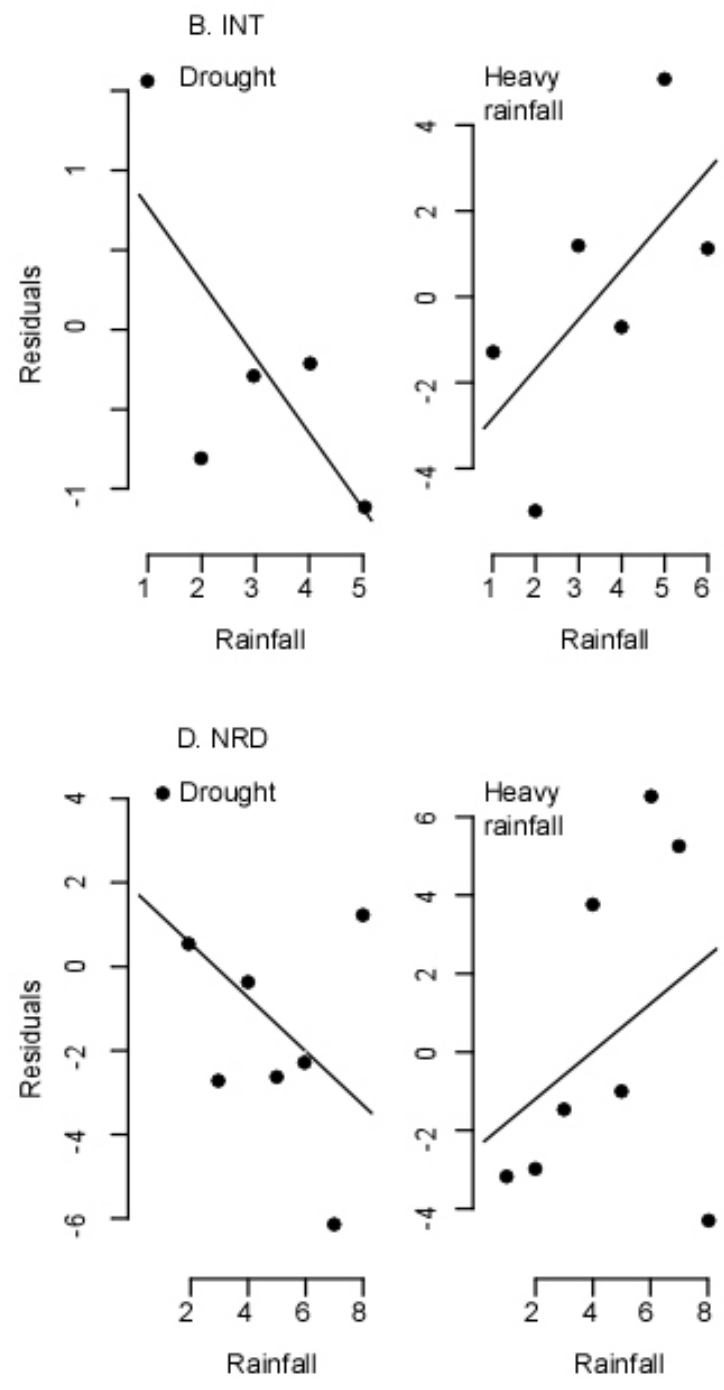

abnormally intense rains at a particular time in the season, that is, the crop being washed away, or the heavy rainfall can be well distributed over the whole season with no particularly intense rains, so it is not associated with particular losses.

\section{Farmers' climatic knowledge and other climatic variables}

Figure 4 presents the results of the same analyses carried out on the other rainfall variables. These results are very similar and can be interpreted in the same way. Thus, for all of them, the number of farmers mentioning drought increased with decreasing rainfall categories (negative linear regression of Pearson's residual), and conversely, the number of losses related to heavy rainfalls increased with rainfall categories (positive linear regression). Again, the farmers' climate knowledge appears more consistent and accurate for extreme climatic values (greater positive or negative residuals values) because farmers' opinions clearly coincide for very dry or very wet seasons, whereas they manifest less clear-cut opinions on seasons when rain variables take intermediate values. Thus, the perception of extreme climatic events is more gradual than abrupt and the Meru farmers' culturally built-in knowledge appears consistent with fuzzy logic.

Drought events reported by farmers matched the variations in the season duration (DUR) particularly well. This suggests 
that this was a key variable constraining the total seasonal precipitation. Reported heavy rainfall events best matched variations in rainfall intensity (INT, defined as the average rainfall amount per rainy day), which pointed to our hypothesis of crop losses in good seasons being predominantly associated with intense rains on certain days in the season.

To ensure that our results were not determined by particular choices in the number of ordered rainfall categories, contingency tables using different numbers of categories (from 4 to 10) were compared. The comparison (Table 2) confirms that the observed linear trend (positive or negative) was not related to the number of rainfall categories retained for the analysis. Thus, the linear correlation coefficient, $r$, between Pearson's residuals and the order of rainfall categories was always negative for drought and positive for heavy rainfall. For all five climatic variables, the proportion of farmers mentioning drought increased as the rainfall values decreased, while the reverse situation was observed for heavy rainfall.

\section{Box 3:}

For all five climatic variables, the proportion of farmers mentioning drought increased as the rainfall values decreased, while the reverse situation was observed for heavy rainfall.

\section{Collective climate knowledge system and contextual meaning}

The remembrance of past rainfall variations by Meru farmers was probably facilitated by their well-defined drought nomenclature. This nomenclature, inventoried during the farmers' group interviews, concerned 11 droughts from 1928 to 2000. Drought in Meru language is referred to as yuura, a term which evokes the sense of crisis caused by extreme and general scarcity of food. The collective climate knowledge system is mainly contextual, referring to non-climatic events (Table 3).

\section{DISCUSSION}

In the present study we aimed to show how accurate the culturally built knowledge of past extreme climatic events is, and how consistent it is with fuzzy logic. Farmers attributed most varietal losses to climatic causes, mostly droughts $(73.5 \%)$ and heavy rainfall $(8.5 \%)$. Their memories presented a striking agreement with past climatic records. Chi-square tests strongly rejected independence between the climatic causes mentioned by farmers and rain gauge recorded rainfall, for both drought and heavy rainfall. Meru farmers agreed in associating remembered drought events to the lowest rainfall values. Meru climate knowledge accuracy was also relatively
Table 2. Association between categories of observed rainfall and Pearson's residuals for reported drought and heavy rainfall events. For each rainfall variable, the linear correlation coefficient ( $r$ ) between Pearson's residuals and ordered rainfall categories was computed considering from 4 to 10 rainfall categories into the analysis. PTOT - seasonal precipitation amount; FREQ - frequency of rainy days; INT rainfall intensity; DUR - seasonal duration; and NRD - number of rainy days.

\begin{tabular}{cccccccc}
\hline \hline & \multicolumn{7}{c}{$\begin{array}{c}\text { Number of ordered rainfall } \\
\text { categories }\end{array}$} \\
\cline { 2 - 7 } & 4 & 5 & 6 & 7 & 8 & 9 & 10 \\
\hline A. DROUGHT & & & & & & & \\
PTOT & -0.6 & -0.62 & -0.91 & -0.8 & -0.62 & -0.55 & -0.59 \\
FREQ & -0.51 & -0.53 & -0.38 & -0.38 & -0.37 & -0.38 & -0.5 \\
INT & -0.21 & -0.72 & -0.55 & -0.25 & -0.2 & -0.29 & -0.22 \\
DUR & -0.88 & -0.63 & -0.65 & -0.53 & -0.59 & -0.53 & -0.46 \\
NRD & -0.81 & -0.59 & -0.6 & -0.55 & -0.51 & -0.41 & -0.44 \\
& & & & & & & \\
B. HEAVY & & & & & & & \\
RAINFALL & & & & & & & \\
PTOT & +0.19 & +0.32 & +0.53 & +0.62 & +0.24 & +0.3 & +0.33 \\
FREQ & +0.55 & +0.53 & +0.23 & +0.22 & +0.28 & +0.15 & +0.26 \\
INT & +0.45 & +0.7 & +0.65 & +0.3 & +0.32 & +0.37 & +0.26 \\
DUR & +0.43 & +0.19 & +0.21 & +0.33 & +0.3 & +0.13 & +0.17 \\
NRD & +0.4 & +0.22 & +0.28 & +0.34 & +0.35 & +0.17 & +0.17 \\
\hline
\end{tabular}

good when they mentioned heavy rainfall events. The proportion of farmers mentioning heavy rainfall increased as rainfall values increased, and was significantly higher at higher rainfall values than at lower values. Similarly to what was observed with drought, the proportion of responses significantly deviates from guessing for the two opposite climatic situations, i.e., wettest and driest years, but allows a large part of guessing for seasons presenting intermediate climatic parameters. Some discrepancies also exist for the wettest years, which may depend on the chosen rainfall variable. Thus, the match between farmers' declarations of heavy rains and observed data was better when daily rainfall intensity was substituted to seasonal rainfall totals.

The high consistency of Meru farmer culturally built-in knowledge with fuzzy logic, confirms the analysis of Berkes and Kislalioglu Berkes (2008) who stated that, with holism, fuzzy logic is a characteristic of the indigenous climate knowledge. In the Meru collective knowledge system, what is a drought (or what it is not) or what is heavy rainfall (or what it is not) is more gradual than abrupt. Meru farmers clearly associate drought with the lowest rainfall values while rejecting the association of drought with higher rainfall values, while their consensus is much weaker for intermediate climatic situations, which seems to leave more space for guessing. Similarly, their perception of heavy rainfall is negatively associated with the lowest rainfalls, and positively associated 
Table 3. Meru drought nomenclature and contextual meaning.

\begin{tabular}{|c|c|c|}
\hline Year & Local name & Contextual meaning \\
\hline 1928 & Yuura ria kwara mururu & The drought of the empty granaries. \\
\hline 1940 & Yuura ria KEA, & $\begin{array}{l}\text { Acronym for the British King's African Rifles army battalion that arrived to contain } \\
\text { the Mau Mau rebellion. }\end{array}$ \\
\hline 1943 & Yuura ria kithioro & $\begin{array}{l}\text { The circles drought. Because of the construction of the road linking the towns of } \\
\text { Meru and Embu, people had to use diversion roads and travel long distances to } \\
\text { obtain food. }\end{array}$ \\
\hline 1948 & Yuura ria Taribo & Named after a white man who donated food to the local people. \\
\hline 1954 & Yuura ria miuu & $\begin{array}{l}\text { The drought of miuu, which is a local tree whose bark was scraped producing a } \\
\text { powder that was cooked and eaten. }\end{array}$ \\
\hline 1965 & Yuura ria Tigania & $\begin{array}{l}\text { The drought of the Tigania, a Meru group where people went to provide labor to } \\
\text { earn food or money. }\end{array}$ \\
\hline 1967 & Yuura ria Kaburia & $\begin{array}{l}\text { In reference to a wealthy business man who owned a shop in the upland. People } \\
\text { traveled from the lowlands to purchase food because he was the only one with } \\
\text { stocks. }\end{array}$ \\
\hline 1979 & Yuura ria kithukio & $\begin{array}{l}\text { The term Kithukio refers to something in large pieces such as meat. There were no } \\
\text { grains to eat and people slaughtered their animals for food. }\end{array}$ \\
\hline 1982 & Yuura ria ngakwa ngwete & $\begin{array}{l}\text { Meaning "I will die holding." People had money but could not find any food to } \\
\text { purchase. Therefore they said that they will die with money in their hands. }\end{array}$ \\
\hline 1984 & Yuura ria $\mathrm{T} 9$ & $\begin{array}{l}\text { Drought of the T9. There were trained dogs named T9 attached to the 9th battalion } \\
\text { of the Tanzania Army used to fight the Government of Dictator Idi Amin Dada of } \\
\text { Uganda. The drought came to be referred to as T9, being equated to the } \\
\text { aggressiveness of the T9 dogs. }\end{array}$ \\
\hline 2000 & Yuura ria nkari tawe & $\begin{array}{l}\text { The drought of "I am as you are." When one went to borrow food from his neighbor, } \\
\text { or any other person in the region, they would reply that they were experiencing a } \\
\text { similar situation, without any food. }\end{array}$ \\
\hline
\end{tabular}

with excessive rainfall, again giving a fuzzy picture in the intermediate climatic situations. Thus, the transition from drought (or heavy rainfall) to less excessive situations is gradual. This fuzzy logic characterizing the Meru climate knowledge was confirmed with all five climate variables used in our study. The gradual transition from an extreme climatic event to a more ordinary one can be understood by considering the indigenous knowledge as collective, rather than individual, and by using the group as the reference to assess the accuracy of the final appreciation.

The Meru drought nomenclature was established in group settings, with five major droughts identified and named from 1928 to 1961 . Because of insufficient rainfall data prior to 1961 , it was not possible to assess properly its accuracy in the light of rainfall records for this distant period. However, the recollection of past extreme climatic events by Meru farmers was probably facilitated by their drought nomenclature, which is based on contextual meaning and association. Remarkably, Meru farmers refer to non-climatic events to remember extreme climatic events.

Preliminary analysis did not show clear relationships between crop losses and the characteristics of the short rains (not shown). A mechanistic explanation can be proposed for why remembering extreme events should matter more for the long rain than the short rain. Long cycle varieties are sown in October at the same time as short cycle varieties. Both long and short cycle varieties are selected by farmers (mass selection) from harvests at the end of the long rains, so that seed availability is crucial at this time. The interannual variations of seasonal rainfall amounts during the long rains are usually strong and poorly predictable, as compared with the short rains; they result from a combination of many features, partly independent from each other, which include variations in onset, occurrence of wet days, rainfall intensity, and cessation date (Camberlin et al. 2009). Lyon and Dewitt (2012) have shown that a significant decrease of seasonal amount occurs in the long rains during the post-1999 period. The difficulty for farmers in predicting the onset, and the irregularity of rainy days, highly increase the risk of farmers' variety losses during the long rains. Remembering past extreme climatic events during this season is thus crucial for farmers.

The comparison of the indigenous and western knowledge has nothing to do with proving the superiority of either one. Assessing the consistency of indigenous climate knowledge with scientific knowledge is only a step to facilitate their integration or association. The two kinds of knowledge correspond to complementary ways of knowing climate, which should help us in developing a contextualized drought monitoring. Drought is an ambiguous concept because climatology, hydrology, or agronomy can define it differently. Drought is probably also differently experienced by farmers cultivating different crops. 


\section{Associating different cultural ways of recording climate variability}

A better understanding of the culturally different approaches of climate variability is essential to ensure collaborative and participatory projects, combining indigenous and western knowledge (Barnhardt 2005, Berkes 2009, Gearheard et al. 2010). In this study, Meru farmers did not express drought severity in terms of rainfall amount, but indirectly in terms of intra-specific crop diversity losses, which itself can be related to rainfall. Gearheard et al. (2010) exploited wind perception to connect Inuit knowledge and meteorological station observations. The wind is one of the most important environmental variables that can either enable or constrain Inuit's hunting activities and travels. There was limited agreement between the two kinds of knowledge, but authors suggested that Inuit observations may not be of the same phenomena, or not fully related to the phenomena that were recorded at the meteorological stations. An indirect assessment of indigenous knowledge thus implies considering how the two phenomena, the one perceived by indigenous people and the one measured by scientists, can be associated.

In the present study, the intra-specific crop diversity losses, as reported by farmers, were related to climate variability, as recorded in meteorological stations. Rainfall records enabled us to find out to what extent the orally reported high-impact climatic events can actually be attributed to droughts or heavy rains; reciprocally, oral reports on seed losses may shed light on which rainfall characteristics have had the most detrimental effects on crops. Drought events reported by farmers match the variations in total seasonal precipitation and the season duration (DUR) particularly well. Heavy rainfall events best match variations in rainfall intensity (INT), which points to the detrimental effect of punctual intense rains rather than a negative effect of cumulated rainfall per se.

Meru past climate knowledge involves cultural and social components. Culturally built-in, this knowledge uses associations in remembering, understanding, and conceiving extreme climatic events. This knowledge is not only climatic per se, it is also economical, i.e., the crop failures that were considered in the present study, sociological (cf. "I am as you are"), or historical (Tanzania Army 9th Battalion), as revealed in the Meru drought nomenclature (see Table 3). However, Meru climate knowledge does not only refer to external factual events. This knowledge is embedded into a social organization. In the Meru society, the succession of age classes and generations, acts as a sociological/climatic clock. Political authority is transmitted every 15 years between generations (gâtiba), in the Meru worldview, according to regular rain and sun cycles, which correspond to the return of drought or heavy rainfall (Peatrik 1999). When the rainfall cycle is back, farmers believe that drought episodes are also back; on the contrary, sun cycles coincide with the return of heavy rainfall. The Meru climatic system, based on successive dry and wet periods, is associated with ideas of "differential prosperity" (Peatrik 1999:81).

As compared with Andean South America farmers that have historically linked stars in the Pleiades to interannual rainfall variability (Orlove et al. 2000), climate knowledge in the Meru society is embedded into the social organization, which is based on the climatic opposition between drought and heavy rainfall. Associating rain and sun cycles, as it is conceived in Meru culture, to climate variability as it is measured in western sciences (Rind 2002), might allow a better understanding of the sun role in climate variations or, indirectly, in crop variety losses.

\section{Fuzzy logic and contextualized drought monitoring}

Some questions remain particularly relevant for the integration of indigenous and western-scientific climate knowledge into a contextualized drought monitoring. What is the cause for the Meru fuzzy picture between the most extreme climatic events in their climate knowledge systems? The Meru drought nomenclature clearly reveals the importance that Meru farmers give to the context in their climate knowledge systems. The fuzzy picture of climatic events probably results from the diversity of contexts, according to which extreme events are differentially experienced by farmers. For drought monitoring, fixing an arbitrary threshold value to distinguish extreme climatic events would not allow considering the diverse contexts where extreme climatic events are experienced by farmers around the world. McKee et al. (1993) propose the standardized precipitation index (SPI), which is based on the difference of precipitation from the mean for a specified time period, expressed in the scale of standard deviation, to delimit "mild drought" (0 to -0.99 sd), "moderate drought," (-1.00 to $-1.49 \mathrm{sd})$, "severe drought" ( -1.50 to -1.99 sd), and "extreme drought" ( $\leq-2.00 \mathrm{sd})$. From quantitative continuous data, drought is apprehended qualitatively, but climatic knowledge is decontextualized. On the contrary, the indigenous climate knowledge gives particular importance to the context.

Smallholder rain-fed agriculture systems are today increasingly dynamic. For example, in the site of our study, farmers responded swiftly to the impulsion of agricultural policies encouraging adoption of maize in place of sorghum and millet in semiarid areas (Ouma et al. 2002, showing increasing rates of adoption from 1965). Although maize is known to be more susceptible to drought than traditional crops such as sorghum and millet, this crop had an undisputable success, gaining a wide acceptance by farmers. Maize became a dominant food crop through the 1990s in Kenya, Zimbabwe, Zambia, and Malawi (Smale and Thom 2003). The threshold values used to distinguish extreme climatic events that are experienced by farmers should consider the agricultural context and its evolution. Under similar climatic conditions, drought can be differently experienced by farmers cultivating 
sorghum or maize because the latter is less resistant to drought. The increasing popularity of maize could imply an increasing risk of agricultural drought that a decontextualized drought monitoring cannot identify.

The spatial variability of rainfall patterns also induces different ecological contexts. The integration of indigenous climate knowledge could allow considering both contextual and climatic data together in drought monitoring. Monitoring tools are common and useful in public health (Lemon et al. 2003) and food insecurity (Borton and Shoham 1991). Drought, as perceived by farmers, given the context, could be used as reference to translate it into contextualized climatologic terms. In such a contextualized drought monitoring, indigenous and scientific knowledge could be complementary, extreme climatic events being defined by referring not only to climatic records but also to people who experienced them.

\section{CONCLUSION}

We aimed to show how accurate the culturally-built knowledge of past extreme climatic events is, and how consistent it is with fuzzy logic. Independence between indigenous climate knowledge and rainfall records was clearly rejected for both drought and heavy rainfall. Indigenous climatic knowledge allows fuzzy pictures of extreme climatic events in intermediate climatic situations. This reflects how extreme climatic events can be differently experienced by farmers, depending on agricultural and ecological contexts. The integration of indigenous and scientific climate knowledge in drought monitoring could allow considering the diversity of contexts where drought affects societies.

Responses to this article can be read online at: http://www.ecologyandsociety.org/issues/responses. php/5896

\section{Acknowledgments:}

This study is a contribution to the PICREVAT project, funded by the French National Research Agency (ANR 08VULN-01-008). We thank Geo Coppens d'Eeckenbrugge (CIRAD, France), Vincent Moron (CERGE, France), Christian Baron (CIRAD, France), Luc Baudouin (CIRAD, France), and anonymous reviewers for their useful comments on the manuscript.

\section{LITERATURE CITED}

Agresti, A. 2007. An introduction to categorical data analysis. Wiley, Gainesville, Florida, USA.

Ambler, C., 1988. The great famine, 1897-1901. Pages 123-149 in C. Ambler, editor. Kenyan communities in the age of imperialism. The central region in the late nineteenth century. Yale University Press, New Haven, Connecticut, USA.

Barnhardt, R. 2005. Indigenous knowledge systems and Alaska Native ways of knowing. Anthropology and Education Quarterly 36(1):8-23. http://dx.doi.org/10.1525/aeq.2005.36.1.008

Berkes, F. 2009. Indigenous ways of knowing and the study of environmental change. Journal of the Royal Society of New Zealand 39(4):151-156. http://dx.doi.org/10.1080/03014220909510568

Berkes, F., and M. Kislalioglu Berkes. 2008. Ecological complexity, fuzzy logic, and holism in indigenous knowledge. Futures 41:6-12. http://dx.doi.org/10.1016/j.futures.2008.07.003

Bojadziev, G., and M. Bojadziev. 2007. Fuzzy logic for business, finance, and management. World Scientific Publishing, River Edge, New Jersey, USA.

Borton, J., and J. Shoham. 1991. Mapping vulnerability to food insecurity: tentative guidelines for WFP country offices. Relief and Development Institute, London, UK.

Camberlin, P., J. Boyard-Micheau, N. Philippon, C. Baron, C. Leclerc, and C. Mwongera. 2012. Climatic gradients along the windward slopes of Mount Kenya and their implication for crop risks. Part 1: climate variability. International Journal of Climatology http://dx.doi.org/10.1002/joc.3427

Camberlin, P., V. Moron, R. Okoola, N. Philippon, and W. Gitau. 2009. Components of rainy seasons' variability in Equatorial East Africa: onset, cessation, rainfall frequency and intensity. Theoretical and Applied Climatology 98 (3-4):237-249. http://dx.doi.org/10.1007/s00704-009-0113-1

Diamond, J., and K. D. Bishop, 1999. Ethno-ornithology of the Ketengban people, Indonesia New-Guinea. Pages 17-46 in L. M. Douglas and S. Atran, editors. Folkbiology. MIT Press, Cambridge, Massachusetts, USA.

Ellen, R., and H. Harris, 2000. Introduction. Pages 1-34 in R. Ellen, P. Parkes, and A. Bicker, editors. Indigenous environmental knowledge and its transformations. Harwood, Amsterdam, The Netherlands.

Ford, J. D., and C. Furgal. 2009. Foreword to the special issue: climate change impacts, adaptation and vulnerability in the Arctic. Polar Research 28:1-9. http://dx.doi.org/10.1111/ j.1751-8369.2009.00103.x

Gearheard, S., M. Pocernich, R. Stewart, J. Sanguya, and H. P. Huntington. 2010. Linking Inuit knowledge and meteorological station observations to understand changing wind patterns at Clyde River, Nunavut. Climatic Change 100:267-294. http://dx.doi.org/10.1007/s10584-009-9587-1 
Green, D., J. Billy, and A. Tapim. 2010. Indigenous Australians' knowledge of weather and climate. Climatic Change 100:337-354. http://dx.doi.org/10.1007/s10584-010-9803$\mathrm{z}$

Green, D., and G. Raygorodetsky. 2010. Indigenous knowledge of a changing climate. Climatic Change 100:239-242. http://dx.doi.org/10.1007/s10584-010-9804-y

Huntington, H. P. 2000. Using traditional ecological knowledge in science: methods and applications. Ecological Applications 10(5):1270-1274. http://dx.doi.org/10.1890/1051-0761 (2000)010[1270:UTEKIS]2.0.CO;2

Huntington, H. P., T. Callaghan, S. Fox, and I. Krupnik. 2004. Matching traditional and scientific observations to detect environmental change: a discussion on Arctic terrestrial ecosystems. Royal Swedish Academy of Sciences 33 (7):20-25.

Lemon, S. C., J. Roy, M. A. Clark, P. D. Friedmann, and W. Rakowski. 2003. Classification and regression tree analysis in public health: methodological review and comparison with logistic regression. Annals of Behavioral Medicine 26 (3):172-181. http://dx.doi.org/10.1207/S15324796ABM2603 02

Lyon, B., and D. G. Dewitt. 2012. A recent and abrupt decline in the East African long rains. Geophysical Research Letters 39:L02702. http://dx.doi.org/10.1029/2011GL050337

Mbithi, P., and B. Wisner. 1973. Drought and famine in Kenya: magnitude and attempted solutions. Journal of East African Research and Development 3:95-143.

McKee, T. B., N. J. Doesken, and J. Kleist. 1993. The relationship of drought frequency and duration to time scales. Pages 179-184 in Preprint, Eighth Conference on Applied Climatology, Anaheim, California. American Meteorological Society, Boston, Massachusetts, USA.

Mertz, O., C. Mbow, A. Reenberg, and A. Diouf. 2009. Farmers' perceptions of climate change and agricultural adaptation strategies in rural Sahel. Environmental Management 43:804-816. http://dx.doi.org/10.1007/ s00267-008-9197-0

Meyer, D., A. Zeileis, and K. Hornik. 2006. The strucplot framework: visualizing multi-way contingency tables with ved. Journal of Statistical Software 17(3):1-48.

Newman, J. L. 1975. Drought, famine, and population movements in Africa. Syracuse University, Syracuse, New York, USA.

Nyamwange, M. 1995. Famine mitigation in Kenya: some practices, impact and lessons. Middle States Geographer 28:37-44.
Ogallo, L. J., S. B. Otengi, P. Ambenje, W. Nyakwada, and F. Githui, 2005. Monitoring agricultural drought: the case of Kenya. Pages 238-251 in V. K. Boken, A. P. Cracknell, and R. L. Heathcote, editors. Monitoring and predicting agricultural drought: a global study. Oxford University Press, New York, New York, USA.

Orlove, B. S., K. Broad, and A. M. Petty. 2004. Factors that influence the use of climate forecasts: evidence from the 1997/98 El Niño Event in Peru. Bulletin of the American Meteorological Society 85:1735-1743. http://dx.doi.org/10.1175/ BAMS-85-11-1735

Orlove, B. S., J. C. H. Chiang, and M. A. Cane. 2000. Forecasting Andean rainfall and crop yield from the influence of El Niño on Pleiades visibility. Nature 403:68-71. http://dx. doi.org/10.1038/47456

Orlove, B. S., C. Roncoli, M. Kabugo, and A. Majugu. 2010. Indigenous climate knowledge in southern Uganda: the multiple components of a dynamic regional system. Climatic Change 100:243-265. http://dx.doi.org/10.1007/s10584-009-9586-2

Ouma, J. O., F. M. Murithi, W. Mwangi, H. Verkuijl, M. Gethi, and H. De Groote. 2002. Adoption of maize seed and fertilizer technologies in Embu district, Kenya. CIMMYT, Mexico City, Mexico.

Özesmi, U. and S. L. Özesmi. 2004. Ecological models based on people's knowledge: a multi-step fuzzy cognitive mapping approach. Ecological Modelling 176:43-64. http://dx.doi. org/10.1016/j.ecolmodel.2003.10.027

Parry, M. L., O. F. Canziani, J. P. Palutikof, P. J. Van Der Linden, and C. E. Hanson, editors. 2007. Cross-chapter case study. Pages 843-868 in Climate change 2007: impacts, adaptation and vulnerability. Contribution of Working Group II to the Fourth Assessment Report of the Intergovernmental Panel on Climate Change. Cambridge University Press, Cambridge, UK.

Patefield, W. M. 1981. Algorithm AS159: an efficient method of generating $\mathrm{R} \times \mathrm{C}$ tables with given row and column totals. Applied Statistics 30:91-97. http://dx.doi.org/10.2307/2346669

Peatrik, A.-M. 1999. La vie à pas contés. Société d'ethnologie, Nanterre, France.

R Development Core Team. 2011. R: A language and environment for statistical computing. $\mathrm{R}$ Foundation for Statistical Computing, Vienna, Austria. [online] URL: http:// www.R-project.org

Rind, D. 2002. The sun's role in climate variations. Science 296(5568):673-677. http://dx.doi.org/10.1126/science.1069562 
Roncoli, C. 2006. Ethnographic and participatory approaches to research on farmers' responses to climate predictions. Climate Research 33:81-99. http://dx.doi.org/10.3354/ $\underline{\mathrm{cr} 033081}$

Roncoli, C., D. Crane, and B. S. Orlove, 2009. Fielding climate change in cultural anthropology. Pages 87-115 in T. Crane and M. Nutall, editors. Anthropology and climate change: from encounters to actions. Left Coast Press, San Francisco, California, USA.

Roncoli, C., K. Ingram, and P. Kirshen. 2002. Reading the rains: local knowledge and rainfall forecasting in Burkina Faso. Society \& Natural Resources 15:409-427. http://dx.doi. org/10.1080/08941920252866774

Salick, J., and N. Ross. 2009. Traditional peoples and climate change. Global Environmental Change 19:137-139. http://dx. doi.org/10.1016/j.gloenvcha.2009.01.004

Smale, M., and J. Thom. 2003. Maize in Eastern and Southern Africa: seeds of success in retrospect. EPTD Discussion Papers 97:1-90.

Vogel, C., and K. O'Brien, editors. 2003. Coping with climate variability: the use of seasonal climate forecasts in Southern Africa. Ashgate, Burlington, Vermont, USA.

Zadeth, L. A. 1965. Fuzzy sets. Information and Control 8:339-353. 